\title{
Commercial effectiveness assessment of implementation the energy efficiency raising of the building project due to introduction of automatic heat consumption control
}

\author{
$Y u . N$. Zvonareva $^{1, *}, Y u . V$. Vankov $^{1}$, and $V . V$. Shlychkov $^{2}$ \\ ${ }^{1}$ Department of Industrial power system and systems of heat supply, Kazan State Power Engineering University-KGEY, Kazan, Russian \\ Federation \\ ${ }^{2}$ Institute of Business \& Innovative Technologies, Kazan National Research Technical University - KAI, Kazan, Russian Federation
}

\begin{abstract}
Introduction of the automated metering stations and regulation (AUU) located directly in the heated building besides creation of comfortable conditions indoors leads to decrease in consumption of thermal energy. The annual expected effect of realization of the offered actions (installation of metering stations and automatic control) can make up to $22 \%$ consumed and that isn't less important, the paid thermal energy. In general, efficiency of implementation of the project on introduction of AUU can be characterized by considerable decrease in heat consumption of the building and, respectively, reduction of a payment for the consumed energy resources. In this paper we evaluated the effectiveness of implementation of increase of energy efficiency of the building investment project (hereinafter SP). We calculated the ratio of expenses and the results considered actions for inhabitants of an apartment house located in Kazan after installation of a weather-dependent regulation. As a result of calculation of the imitating model created on the basis of basic data and the investment project plan the main results of determination of economic efficiency of the Project have been received. For the analysis and increase of reliability of a settlement assessment of efficiency of the investment project calculations at different options of a set of basic data are executed.
\end{abstract}

\section{Introduction}

Optimal thermal energy consumption in compliance with the required comfort in rooms of buildings is the main objective of energy saving in the sphere of municipal heat supply to which much attention is paid today.

According to experts, excess heat consumption of the housing stock is about $30-40 \%[1,2]$.

Along with power inefficient use of thermal energy, annually there is a growth of tariffs. For example, during 2010-2015 in Kazan growth of a tariff was 36,1\% for thermal energy.

Introduction of the automated thermal points (AITP) so popular for today allows to carry out complex regulation of thermal energy consumption for needs of heating and hot water supply of object according to his actual requirements. It gives the opportunity to save means of thermal energy suppliers and its consumers considerably. The greatest economic effect of introduction of AITP is reached in the conditions of the centralized systems of heat supply in which there are seasonal (autumn-spring) "overheating", according to the operational data reaching $30 \%$ of annual settlement consumption $[3,4,5]$.

\section{Goals and objectives}

Earlier we published the results of researches which showed that upon transition from TsTP to ITP the actual decrease of thermal load for heating residential apartment houses, averages 30,4\% [6]

For an assessment of effectiveness of implementation the energy efficiency of the building investment project (hereinafter the SP) carried out calculation of expenses and results ratio of average 9-floor residential apartment house located in Kazan [7].

The purpose of this work is providing to investors the information about the investment project sufficient for decision-making of expediency of participation in its realization.

The assessment of commercial effectiveness of SP was carried out taking into account the following requirements $[8,9]$ :

- the capital investments put in calculations are indexed according to price indexes for capital investments and elements of its technological structure;

- all calculations - in rubles of the Russian Federation;

- all calculations are executed including VAT;

- the cost of installation works is accepted the partner company, equal according to calculations;

- design cost wasn't taken into consideration. 
The assessment of indicators of efficiency of investments on the considered object was made according to the "Methodical recommendations about an assessment of investment projects efficiency" approved by the Ministry of Economics of the Russian Federation, the Ministry of Finance of the Russian Federation, the State committee of the Russian Federation on construction, architectural and housing policy (to No. BK 477 of June 21, 1999).

Financial and economic calculations are executed with using the certified computer program "Project Expert 7.55" developed by the Expert Systems firm (Moscow) intended for the creation and the analysis of financial model of a new which yet isn't created or already operating enterprise regardless of its branch accessory and scale that allows to define the main indicators of economic efficiency on the basis of the integrated indicators and expected economic estimates [10].

As capital investments are taken the investments in a volume necessary for implementation of the project.

All types of integrated results and expenses are expressed and compared in the discounted form.

The model of cumulative construction (CCM), as the most adequately reflecting discounting indicators for objects of power branch is applied to calculation of a discount rate. In this method the discount rate is the sum of a risk-free rate of profitability and set of awards for the separate, relating to this project risks estimated in the expert way.

The general discount rate pays off as the sum of all components and by results of calculation is accepted equal $13,75 \%$ [11].

In calculations were considered value added taxes, income tax, the property tax.

Taxation rates on each of points are accepted according to the tax code of the Russian Federation.

\section{Results and discussion}

In the course of work generated the indicators by groups of objects of inflation which characterize changes of receipts cost and payments under the main articles of the project in accordance with expected macroeconomic indicators.

In work was carried out the integrated assessment of energy efficiency increase project of heating system in a house.

Volumes of necessary capital investments for implementation of the project are determined proceeding from the integrated estimation of cost of the main and auxiliary, costs of the installation and construction works (ICW), and also an other expenses $[12,13]$. The data provided by producers and suppliers of the equipment, contract organizations, cost indexes of similar objects in the territory of the Russian Federation, and also information and analytical materials on power branch are assumed as a basis.

The total cost of the project makes 430,476 thousand rubles.
Duration of the project is accepted 240 months (20 years) that corresponds to AUU service life declared by the producer. The beginning of the project is set: 01.08.2015 y.

For the planned volume of deliveries was accepted the calculated value of economy of thermal energy after the AUU installation for an assessment of economic efficiency of the considered project it according to the earlier calculations [14].

As a result of calculation of the imitating model created on the basis of original data and the investment project plan the main results of determination of economic efficiency of the Project were received.

Results of calculation are reduced in Table 1.

Table 1. Main Financial perfomanceable.

\begin{tabular}{|c|c|}
\hline Indicator & Value \\
\hline $\begin{array}{c}\text { Simple period of payback of initial } \\
\text { expenses (RB), m }\end{array}$ & 31 \\
\hline $\begin{array}{c}\text { The discounted period of payback of Initial } \\
\text { expenses (DPB), } \mathrm{m}\end{array}$ & 35 \\
\hline $\begin{array}{c}\text { Average standard of profitability (ARR) on } \\
\text { the project, \% }\end{array}$ & 51,55 \\
\hline The net provided income (NRV), rub & 1055747,4 \\
\hline Index of profitability (PI) & 3,45 \\
\hline Internal standard of profitability (IRR), $\%$ & 66,6 \\
\hline
\end{tabular}

Ratio of the discounted and simple period of payback of initial expenses are presented in Figure 1.

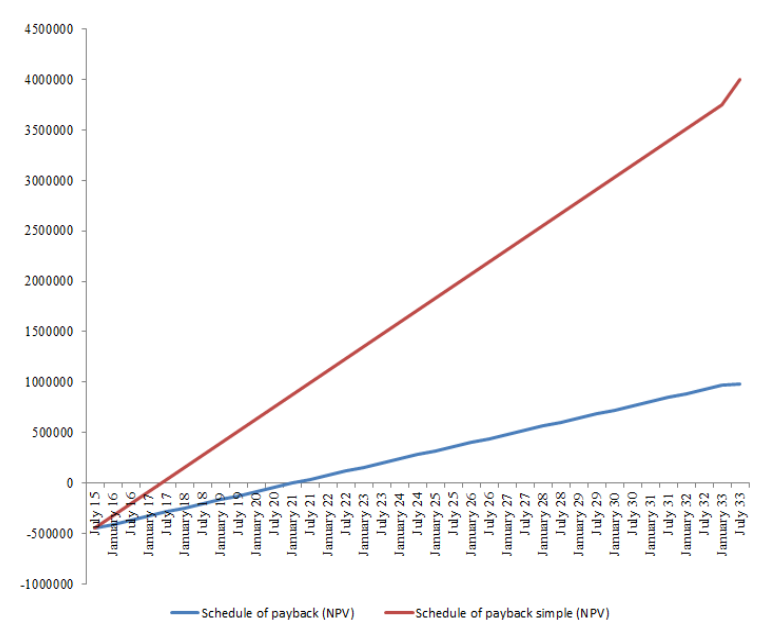

Fig. 1. Schedule of payback (NPV).

Thus, proceeding from the analysis of indicators of economic efficiency [15], the considered versions of the project are economically expedient.

For the analysis and increase of reliability of a settlement assessment of the investment project efficiency are executed the calculations at different options of a set of basic data, such as:

- price of realization of finished goods (heat carrier);

- costs of production (direct charges);

- general investment expenses;

- production sales volume (the thermal charge consumed by the considered costumer).

Range of change of above-mentioned factors from$50 \%$ to $+50 \%$ with a step of $10 \%$. 
Results of calculations for each of the considered options are presented in the form of schedules in Figures 2-4.

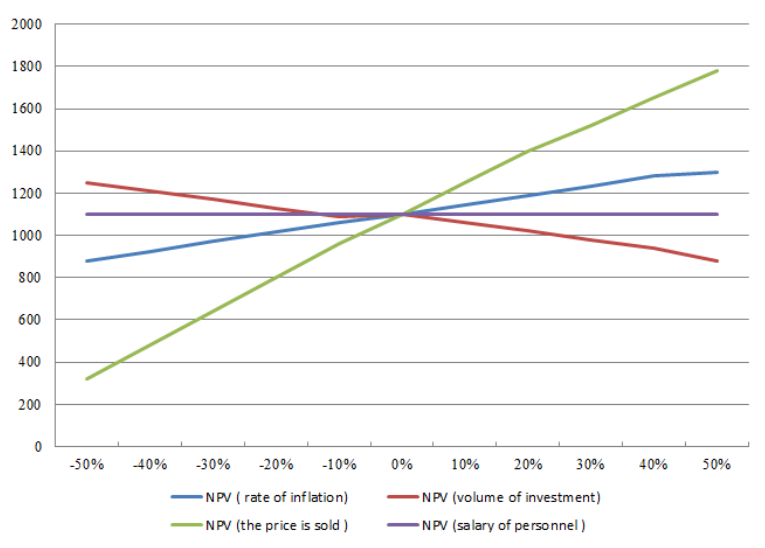

Fig. 2. Analysis of sensitivity (NPV).

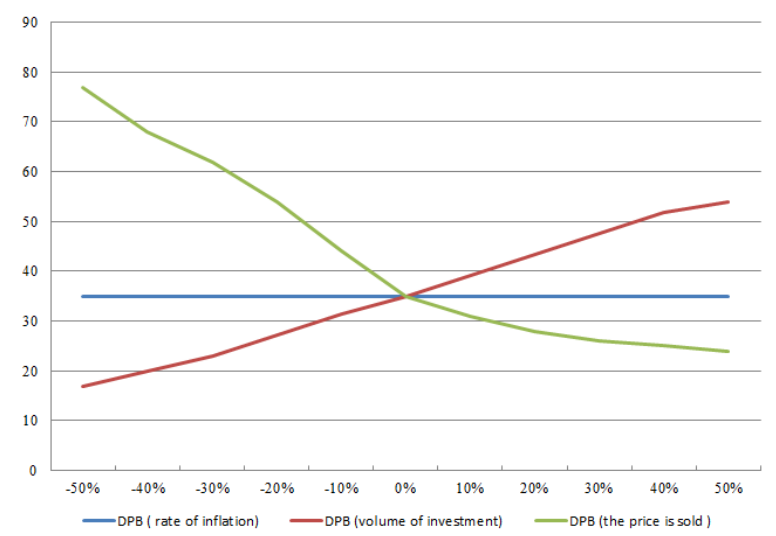

Fig. 3. Analysis of sensitivity (DPB), m.

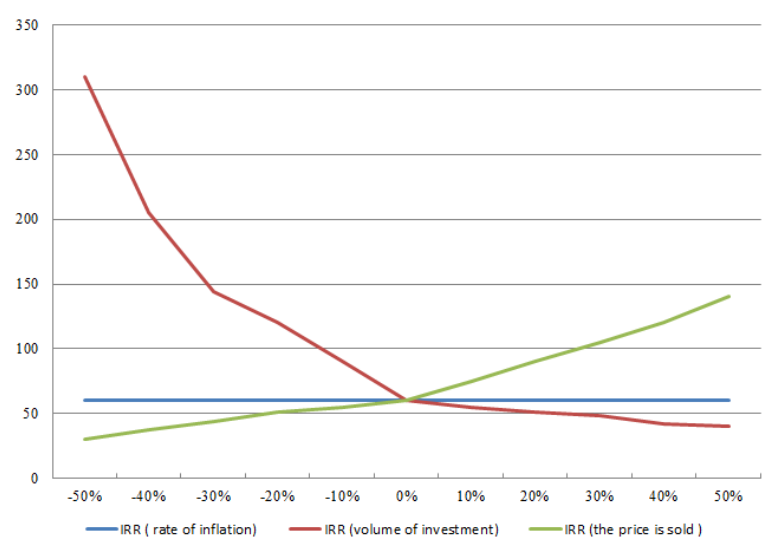

Fig. 4. Analysis of sensitivity (IRR), \%.

The analysis of the results received due to calculations showed:

1. At change of tariffs there is a change of NPV coinciding in the direction and the return change of a payback period.

2. The change in price of fuel leads to the unidirectional change of a payback period and back influences the net discounted income and has smaller impact on indicators of payback of the project, than change of tariffs.

3. The increase in cost of the equipment leads to decrease in economic indicators.
It should be noted that at all considered changes the project remained steady.

In the considered range of deviations $(+/-50 \%)$ the Project remains profitable irrespective of the following factors:

- at increase in cost of raw materials and materials (direct expenses) from planned by every year;

- at increase in the volume of investment.

The given researches of economic risk factors allow to note high stability of the main indicators characterizing efficiency of the project: the net discounted income, the internal standard of profitability, the index of profitability and a payback period. The considered project turned out to be the most sensitive to change of a tariff for thermal energy $[16,17]$.

Stability of the project is caused by existence of a stable sales market of thermal energy.

The risk on the project can be caused by the following reasons:

- increase in the volume of investment in connection with instability of an economic situation;

- change of the size of tariffs for net output of thermal energy.

\section{Conclusion}

Capital expenditure from 430,746 thousand rubles is necessary for the realization of actions the energy efficiency increase project of heating system of the considered average house.

The annual expected effect from realization of the offered actions can save up to $30,4 \%$ consumed and, that isn't less important, the paid thermal energy $[18,19]$.

In terms of money, according to a tariff for thermal energy for $2015 \mathrm{y}$. a decrease in heat consumption will allow homeowners to reduce the cost of the provided services for the sum about 347,52 thousand rubles with VAT in a year. Thus it should be noted that due to annual growth of tariffs for thermal energy, the economy will increase.

The carried-out calculations showed that the internal standard of profitability of the Project is more than chosen discount rate, and it indicates a high degree of the Project reliability and small dependence on change of investment climate.

According to experts, capital expenditure for introduction of AUU at average useful service of the capital equipment of 20 years, pays off for the period from 3 to 3,5 years [20].

For our Project the simple payback period (taking into account growth of a tariff) made 2 years and 7 months, and taking into account discounting - 2 years 11 months.

In general, efficiency of implementation of the Project can be characterized by considerable decrease in heat consumption of the building and, respectively, by reduction of a payment for the consumed energy resources. 


\section{References}

1. A. Chistovich, The Russian Expert review, 2 (2006). http://www.protown.ru/information/articles/3325.ht $\mathrm{ml}$.

2. B.E. Korenkov, I.A. Smirnov, L.P. Needle, Power system, 11 (1992)

3. B.M. Madorskij, V.A. Shmidt, Operation of central heat distribution stations, systems of heating and hot water supply (Moscow, 1971)

4. I.S. Shein, A.V. Izvekov, Some questions of optimization of functioning of city thermal knot. Radio electronics, electrical equipment and power (MEI, Moscow, 2010)

5. B.V. Sazanov, Thermal power plants: Manual for technical schools of heat power specialties (Energy, Moscow, 1974)

6. Yu.N. Zvonareva, Yu.V. Vankov, Proc. 21 century: fundamental science and technology VII, USA, 2, 131-133 (2015)

7. Yu.N. Zvonareva, Yu.V. Vankov, L.A. Polenov, L.A. Pavlov, Energy Resource and energy conservation in the Republic of Tatarstan, 77-79 (2015)

8. V.E. Popov, Regional economy, 1, 59-69 (2009)

9. E.Ya. Sokolov, Central heating and thermal networks (MEI publishing house, Moscow, 2001)
10. T.A. Volosatova, Inženernyj vestnik Dona, 4 (2013). ivdon.ru/ru/magazine/archive/n4y2013/2054.

11. I.S Shein, A.V. Izvekov, Reliability and safety of power, 2(17) (2012)

12. L.O. Dikul, Economy, statistics and informatics, 4, 30-35 (2011)

13. Yu.N. Zvonareva, Proc. Engineering and technology (2014)

14. Yu.N. Zvonareva, Yu.V. Vankov, The Tomsk Polytechnic University, 11 (2015)

15. Employment of Danfoss automation at heating points of systems of central heat supply of buildings. Benefit. RB.00.H8.50 (OOO Danfoss, Moscow, 2014)

16. M.F. Drigo, Management in Russia and abroad, 1, 18-24 (2008)

17. V.V. Pyrkov, Modern thermal points. Automatic equipment and regulation (Takispravi, 2007)

18. Yu.N. Zvonareva, Proc. Radio electronics, Electrical equipment and Power (2012)

19. Yu.N. Zvonareva, Yu.V. Vankov, S.A. Nazarychev, Engineers Don Gazette, 4 (2015). ivdon.ru/ru/magazine/archive/n4y2015/3315.

20. T.A. Makarenja, S.V. Stash, Inženernyj vestnik Dona, 3 (2013). ivdon.ru/magazine/archive/n3y2013/1839/. 